\title{
Cinco minutos de Positivismo Jurídico
}

\author{
Eduardo Valory ${ }^{1}$
}

\begin{abstract}
RESUMO
Em 12 de setembro de 1945, após doze anos de regime nacional-socialista e seis anos de mais uma guerra mundial, Gustav Radbruch, um dos mais conhecidos juristas e filósofos do Direito da Alemanha, fez circular entre os alunos da Faculdade de Direito de Heidelberg o conhecido texto "Cinco minutos de filosofia do Direito", de sua autoria. Neste breve e enfático escrito, em síntese, atribui ao positivismo jurídico as responsabilidades pelas barbáries e arbitrariedades cometidas pelos nazistas, sob as proteções do Direito, ao longo de seu período no poder. O artigo que se segue pretende não só contestar o libelo de Radbruch contra o positivismo desmistificando e desconstruindo boa parte das confusões e incompreensões que foram erguidas a partir das equivocadas conclusões deste jusfilósofo - como, neste percurso, oferecer algumas perspectivas sobre o conceito de positivismo jurídico.
\end{abstract}

PALAVRAS-CHAVES: positivismo jurídico; Radbruch; cinco minutos.

\section{Five minutes of Legal Positivism}

\begin{abstract}
On semptember 12,1945 , after twelve years of the national-socialist regime and six years of another world war, Gustav Radbruch, one of the most notable jurists and legal philosophers of Germany, circulated among the students of Heidelberg Law School his famous text "Five minutes of Legal Philosophy". In this concise and emphatic work, in sum, attributes to legal positivism the responsibilities for the savagery and arbitrariness committed, under the law protection, by the nazi. The following paper pretends not only to refute the Radbruch's criticism against positivism demystifying and deconstructing most of the confusions and misunderstandings built from the wrong conclusions of this Legal Philosopher - but also, in this journey, offers some perspectives on the concept of legal positivism.
\end{abstract}

KEY WORDS: Legal positivismo; Radbruch; five minutes.

\footnotetext{
${ }^{1}$ Mestrando em Teoria e Filosofia do Direito na UERJ. Pós- Graduado em Direito Público e Privado. Graduado em Direito pela PUC. E-mail: evalory@ hotmail.com . Versão em português recebida em 17/10/2012, aceita em 27/11/2012, e autorizada para 30/06/2013.
} 


\section{Introdução}

Em 12 de setembro de 1945, após doze anos de regime nacional-socialista e seis anos de mais uma guerra mundial, Gustav Radbruch, um dos mais conhecidos juristas e filósofos do Direito da Alemanha, fez circular entre os alunos da Faculdade de Direito de Heidelberg o

conhecido texto "Cinco minutos de filosofia do Direito", de sua autoria. Neste breve e enfático escrito, em síntese, atribui ao positivismo jurídico as responsabilidades pelas barbáries e desmandos cometidos pelos nazistas, sob as proteções do Direito, ao longo de seu período no poder; com suas palavras, sustenta que "esta concepção da lei e sua validade, a que chamamos Positivismo, foi a que deixou sem defesa o povo e os juristas contra as leis mais arbitrárias, cruéis e criminosas" (Radbruch, 2009, p. 69) ${ }^{2}$. A análise detalhada das críticas ao positivismo jurídico nos demonstra que a maior parte das objeções lançadas contra esta concepção de estudo do Direito se baseia exatamente nas mesmas distorções teóricas e incoerências históricas que se faziam presentes nesta produção de Radbruch - escrito que, não se faz necessário ressaltar, aparece em momento de extrema consternação e tormento para os pensadores comprometidos com noções humanistas. A revisão das idéias destes cinco minutos de filosofia do Direito, portanto, revela-se tanto essencial para a correta inteligibilidade do positivismo jurídico, como necessária para um debate mais sóbrio sobre suas propostas. $\mathrm{O}$ artigo que se segue, assim, pretende não só contestar o libelo de Radbruch contra o positivismo - desmistificando e desconstruindo boa parte das confusões e incompreensões que foram erguidas a partir das equivocadas conclusões deste jusfilósofo - como, neste percurso, oferecer algumas luzes sobre o conceito de positivismo jurídico. Objetivando contrapor mais claramente os argumentos, a estrutura expositiva segue o feitio adotado por Radbruch em seu texto original, ou seja, uma dissertação sumária, fluida e separada por "minutos".

\section{Primeiro minuto}

Ordens são ordens, é a lei do soldado. A lei é a lei, diz o jurista. No entanto, ao passo que para o soldado, homem incumbido de ações práticas, sempre resta a possibilidade de opor-se à obediência de ordens que considera iníquas, ao jurista, como estudioso do Direito e não seu criador ou aplicador, exceções desta natureza não têm sentido, vez que não lhe cabe discutir a justiça (o valor) das leis ou a conveniência social de sua concreta observância pelos cidadãos, mas sim a descrição e estudo dos preceitos jurídicos que possuem efetiva vigência em uma determinada sociedade. A lei, como uma das espécies de normas que pretendem direcionar a conduta humana, vale (a validade) por ser lei, independentemente de sua possível e eventual compatibilidade com ditames morais pressupostos; é lei sempre que, em uma análise empírica ${ }^{3}$,

\footnotetext{
${ }^{2}$ As críticas ao positivismo jurídico e as conclusões sobre a responsabilidade desta abordagem pelos atos do nazismo se repetem em produções posteriores de Radbruch, principalmente em "Arbitrariedade legal e Direito-supralegal" e "A renovação do Direito", ambos de 1946.

${ }^{3}$ O termo "empírico" é utilizado no texto para exprimir a essência comum a todas as correntes juspositivistas: a exigência teórica da possibilidade de constatação fática da existência de determinadas normas em um específico agrupamento social. Advirta-se, portanto, que na presente obra "empírico" se relaciona ao denominado "positivismo
} 
constatem-se que suas prescrições possuem obrigatoriedade e a capacidade de se imporem e tornarem-se efetivas em sociedade.

Esta concepção de estudo do Direito ou, para alguns, Ciência Jurídica a que chamamos positivismo jurídico, gênero abrangente de muitas, variadas e contrastantes escolas ${ }^{4}$, não é responsável - como vulgarmente se entende - por deixar indefesos o povo e os aplicadores do Direito contra leis arbitrárias, cruéis e criminosas que vigoram e vigoraram nos mais diversos regimes opressores e totalitários ao longo da história. Não foi o jurista positivista, como teórico que apenas identifica e discorre sobre o Direito vigente, o culpado pela existência ou cumprimento destes preceitos, sequer recomendando ou postulando o dever de se dar concreção a estes mandamentos abomináveis, problema que, entregue às vicissitudes da realidade política, depende exclusivamente das correlações fáticas de poder em uma dada sociedade.

\section{Segundo minuto}

Não há dúvidas que muitos foram os déspotas e governos que, sob a pretensa justificativa de realizar os interesses do povo, a igualdade ou o bem comum, implantaram, por meio do Direito, verdadeiros impérios de terror que despojaram a totalidade de seus cidadãos - ou parcelas de suas populações - das mais básicas e fundamentais garantias, anseios e aspirações inerentes às suas condições de seres humanos. Entretanto, apesar do positivismo reconhecer a qualificação jurídica de tais ordenamentos arbitrários, não advoga que "aquilo que os detentores do poder do Estado julgarem conveniente para o bem comum, os caprichos de um déspota, as penas decretadas sem lei ou sentenças anteriores" (Radbruch, 2009, p. 70), deverão ser o conteúdo do Direito ou que tais normas jurídicas deverão ser aplicadas. Os juristas positivistas não são os legisladores de tais preceitos, muito menos juízes da moral de um dado sistema jurídico. Como estudiosos do Direito em vigor, diferenciam a contemplação da realidade que se mostra evidente como um fato, a norma jurídica que "ê", dos mandamentos que deveriam ser adotados por uma concepção qualquer de justiça - as normas que "deveriam-ser" vigentes.

No cerne no positivismo jurídico, como se sabe, encontra-se a rejeição de toda e qualquer formulação metafísico-idealista de um Direito a priori determinado por conteúdos de origem divina, do direito natural ou de deveres oriundos de uma reflexão racional absoluta. Exatamente de encontro a este alicerce do positivismo, muito ao contrário, Hans Kelsen ${ }^{5}$ salienta que, em uma

conceitual" e à "tese do fato social". Sobre estes conceitos fundamentais ao debate sobre o positivismo jurídico, v. NINO, Carlos Santiago. Introdução à análise do Direito. Trad. de Elza Maria Gasparotto. São Paulo: Ed. Martins Fontes, 2010, pp. 42-50; DIMOULIS, Dimitri. Positivismo Jurídico: introdução a uma teoria do direito e defesa do pragmatismo jurídico-político. São Paulo: Ed. Método, 2006, p. 78 e seguintes; e HOERSTER, Norbert. En defensa del positivismo jurídico. Trad. de Ernesto Garzón Valdés. Barcelona, España: Ed.Gedisa, 2000, pp. 9-27.

${ }^{4}$ Ao final do "quarto minuto" faz-se uma breve elucidação sobre as duas principais correntes positivistas envolvidas nos debates contemporâneos.

${ }^{5}$ Sobre o ponto, conferir as obras de Hans Kelsen sobre as relações entre as concepções de justiça e as organizações políticas, especialmente KELSEN, Hans. Teoria General del Estado. México: Ed. Ediciones Coyocán, 2008, p. 470473; KELSEN, Hans. Absolutismo e relativismo na filosofia e na política. In KELSEN, Hans. A Democracia. 2. ed. 
análise histórica, desde a antiguidade clássica se observaria uma intimidade entre as doutrinas políticas autoritárias, totalitárias e anti-humanistas com os discursos de identificação do Direito com as normas de uma pressuposta "Justiça" independente das humanas, demasiadamente humanas, vontades e leis positivamente estabelecidas. Para ater-se somente ao século XX, no Estado fascista Italiano e seu "sentimento dello Stato"; na Alemanha nacional-socialista e suas noções de "volksgemeinschaft" (comunidade do povo) e "volksgeist" (espírito do povo); e, por fim, na URRS e seu Direito voltado para a realização da "vontade revolucionária do proletariado" (ou "vontade de todo o povo", como se passou a afirmar posteriormente), o que se observa é um deliberado abandono e amesquinhamento dos costumes jurídicos, do primado da legalidade e dos princípios do Estado de Direito em nome de normas e objetivos de "justiça" que deles independeriam. Ou seja, o que se constata nas mais diferentes ditaduras do último século, na linha da ampla maioria do pensamento político antidemocrático e sem dever nada aos diversos jusnaturalismos, é uma forte atitude antipositivista ${ }^{6}$.

\section{Terceiro minuto}

O conceito de Direito é um dos temas mais controvertidos no pensamento jurídico e filosófico. Se aos químicos e biólogos pode parecer um tanto quanto inusitado que a definição geral de uma disciplina de estudo possa gerar tantas contendas e debates, a pergunta "O que é o Direito?", ao contrário, sempre integrou - e ainda integra - grande parte das discussões do meio jurídico. Tal se dá, em uma primeira perspectiva, pela própria ambiguidade e vagueza da palavra "direito", bem como seu emprego inapropriado da linguagem. Como termo ambíguo, "direito"

São Paulo: Ed. Martins Fontes, 2000; KELSEN, Hans. Fundamentos da democracia. In KELSEN, Hans. A Democracia. 2. ed. São Paulo: Ed. Martins Fontes, 2000, principalmente página 195 e ss.

${ }^{6}$ Cf. NOVAIS, Jorge Reis. Contributo para uma teoria do Estado de Direito. Lisboa, Portugal: Ed. Almedina, 2006, Capítulo V; BOBBIO, Norberto. O positivismo jurídico: lições de Filosofia do Direito. São Paulo: Ed. Ícone, 2006, p. 236; VAN CAENEGEM, R. C. Uma Introdução Histórica ao Direito Constitucional Ocidental. Lisboa, Portugal: Ed. Calouste Gulbenkian, 2009, pp. 298 - 347. Especificamente quanto ao nazismo, LOSANO, Mario G. Sistema e estrutura no Direito. Volume II. São Paulo: Ed. Martins Fontes, 2010, Capítulo V, e MÜLLER, Ingo. Los Juristas del Horror. Bogotá, Colombia: Ed. Alvaro Nora, 2009, especialmente o Capítulo 6, da Segunda Parte, e o Capítulo 3, da Terceira Parte. Tratando do sistema jurídico soviético e os paradoxos da "legalidade socialista", RAÓ, Vicente. $O$ Direito e a Vida dos Direitos. 6 ${ }^{\text {a }}$. São Paulo: Ed. Revista dos Tribunais, 2004, Capítulo 5. É o que também conclui Hannah Arendt: “(...)Nunca se pôs em dúvida que o governo legal e o poder legítimo, de um lado, e a ilegalidade e o poder arbitrário, de outro, são aparentados e inseparáveis. No entanto, o totalitarismo nos coloca diante de uma espécie totalmente diferente do governo. É verdade que desafia todas as leis positivas, mesmo ao ponto de desafiar aquelas que ele próprio estabeleceu (como no caso da Constituição Soviética de 1936, para citar apenas o exemplo mais notório) ou que não se deu ao trabalho de abolir (como no caso da Constituição de Weimar, que o governo nazista nunca revogou). Mas não opera sem a orientação de uma lei, nem é arbitrário, pois afirma obedecer rigorosa e inequivocamente àquelas leis da Natureza ou da História que sempre acreditamos serem a origem de todas as leis. A afirmação monstruosa e, no entanto, aparentemente irrespondível do governo totalitário é que, longe de ser "ilegal”, recorre à fonte de autoridade da qual as leis positivas recebem a sua legitimidade final; que, longe de ser arbitrário, é mais obediente a essas forças sobre-humanas que qualquer governo jamais foi; e que, longe de exercer o seu poder no interesse de um só homem, está perfeitamente disposto a sacrificar os interesses vitais e imediatos de todos à execução do que supõe ser a lei da História ou a lei da Natureza. O seu desafio às leis positivas pretende ser uma forma superior de legitimidade que, por inspirar-se nas próprias fontes, pode dispensar legalidades menores. A legalidade totalitária pretende haver encontrado um meio de estabelecer a lei da justiça na terra - algo que a legalidade da lei positiva certamente nunca pôde conseguir." (ARENDT, 2009, pp. 513-514) 
pode significar, dentre outros, um conjunto coordenado de normas (sistema jurídico), um interesse juridicamente protegido (direito subjetivo), uma determinada perspectiva de correção de um comportamento humano (direito como justiça) ou a própria disciplina de estudo do Direito (a Ciência Jurídica ou Teoria do Direito). Como vocábulo vago não oferece, pela estrita e abstrata análise de suas propriedades significativas, uma essência ou qualidade intrínseca que independa de observações da realidade social e das regras convencionais de seu emprego na linguagem ${ }^{7}$. Para complicar ainda mais a questão, é comum entre os doutrinadores a confusão entre dois níveis absolutamente distintos de linguagem: o plano da metalinguagem, das proposições que pretendem oferecer conhecimentos sobre a realidade jurídica - ocupado pela Ciência ou Teoria do Direito, e o plano da linguagem prescritiva de mandamentos, identificado com as proposições linguísticas que enunciam normas sobre comportamentos que deverão ser juridicamente vinculantes - o Direito propriamente caracterizado.

Em uma segunda perspectiva, muitas das divergências ao redor da conceituação do Direito se devem às inconformidades e diversidades de ideais entre o conteúdo do Direito e os valores admitidos como desejáveis por um determinado observador. Diversos juristas, renegando as diretrizes do positivismo jurídico, se atribuem o poder e, até mesmo, o dever de avaliarem e julgarem a justiça e obrigatoriedade dos preceitos jurídicos. Para estes, as normas de um ordenamento só seriam jurídicas se estivessem em conformidade com um específico conjunto de prescrições: o Direito, para ser Direito, deveria ter suas prescrições compatíveis com a vontade dos deuses, com o direito natural ou, mais atualmente, com uma moral que se torna evidente pelo emprego da razão ou por adesão popular.

Embora existam diversas correntes no interior do positivismo jurídico, duas características comuns deste movimento podem ser de plano identificadas: a) o positivismo jurídico considerados seus representantes desde o início do século passado ${ }^{8}$ - é uma postura filosóficojurídica relacionada estritamente à metalinguagem do Direito, quer dizer, é proposta teórica que diz respeito ao estudo e exame do Direito, não à determinação do conteúdo normativo das prescrições que são analisadas; b) seus adeptos, pretendendo unicamente apreender e produzir conhecimentos sobre as normas efetivamente em vigor (objeto de estudo de sua disciplina), separam o Direito, enquanto conjunto de mandamentos de conduta dotados de obrigatoriedade e verificáveis empiricamente em uma sociedade qualquer, das prescrições que deveriam ser incorporadas por imperativos de justiça ou conveniência popular. Com outras palavras, os teóricos positivistas entendem que as normas do Direito são jurídicas independentemente de suas justiça (moralidade) ou legitimidade (consciência política dos sujeitos a elas submetidos); os positivistas jurídicos diferenciam a validade das normas da valoração do seu conteúdo.

\section{Quarto minuto}

\footnotetext{
${ }^{7}$ São estas as demonstrações de Carlos Santiago Nino, em NINO, Carlos Santiago. Introdução à análise do Direito. São Paulo: Ed. Martins Fontes, 2010, pp. 11-17. Para uma introdução às perplexidades relacionadas à resposta à pergunta "O que é o Direito?", vede HART, Herbert. $O$ conceito de Direito. $5^{\mathrm{a}}$ ed. Lisboa, Portugal: Ed. Calouste Gulbenkian, 2007, Capítulo I.

${ }^{8}$ Trata-se aqui, principalmente, de Hans Kelsen, Alf Ross e Herbert Hart.
} 
A extensa maioria das acusações lançadas por Radbruch, entretanto, não só não refletem a realidade do pensamento dos jusfilósofos positivistas - ao menos desde o início do século passado, repita-se - como demonstram uma completa incompreensão de suas idéias. Como observação geral preliminar de muita importância e que, no entanto, é objeto de grosseiras confusões na doutrina, ressalte-se que o Direito positivo de que trata o positivismo jurídico não se identifica com o "Direito codificado", a lei escrita e formalizada, ou com as normas incluídas em qualquer instrumento legislativo solene. Embora estas constituam as fontes mais comuns do Direito nos países de tradição jurídica romano-germânica e sejam, sem dúvida, origens do Direito positivo, também os usos e costumes são identificados pelos positivistas como fontes do Direito positivo - que, como é de conhecimento geral, inclusive representam a maior parte da "legislação" nos países adeptos da Common Law. Direito positivo não significa Direito estatutário - este é o pertencente a um documento legal qualquer, aquele revela-se como um conjunto de normas decorrentes de vontades humanas e acompanhadas da capacidade de se imporem!

O positivismo jurídico não defende - ao contrário das doutrinas jusnaturalistas e moralistas - que a lei, por ser lei, seria ou deveria ser, consequentemente, justa; quer dizer, jamais pretendeu extrair da mera constatação da validade jurídica de determinados preceitos a sua conformidade com ideais de justiça. Da mesma maneira, não afirma que uma vez verificada a vigência de uma norma jurídica qualquer esta deveria, de fato e obrigatoriamente, ser observada pelos cidadãos, cumprida pelas autoridades ou aplicada pelos órgãos judiciários do Estado; como corrente relacionada ao estudo do Direito, entende não lhe competir lançar juízos sobre esta questão que extravasa os seus domínios ${ }^{9}$. Outra crítica inadequada que muito se difunde sobre o pensamento positivista é a chamada "aplicação mecânica do Direito", que credita aos positivistas a tese de que os órgãos aplicadores do Direito, especialmente os juízes, teriam por dever e função a mera subsunção, quase automática e irrefletida às nuances do caso concreto, dos fatos às normas jurídicas existentes. Os positivistas jurídicos foram, diferentemente, os primeiros juristas a sustentar e demonstrar que a linguagem do Direito possui ambiguidades, vaguezas e amplitudes semânticas que impossibilitam quaisquer pretensões de um procedimento parecido ${ }^{10}$.

Dentro do gênero de pensamento positivista atual há uma diferenciação entre duas espécies distintas de positivismo jurídico. De um lado temos os positivistas exclusivistas, autores como Hans Kelsen, Alf Ross e Joseph Raz, que observam o fenômeno jurídico como autônomo e independente de interações com os sistemas de moralidade presentes em uma específica sociedade; de outro lado temos os positivistas inclusivistas, como Neil MacCormick, Wilfrid Waluchow e, que no Brasil maior projeção possui, Herbert Hart reconhecendo que embora a validade do Direito não se submeta a uma necessária conformidade com normas de moralidade, diagnosticam que os imperativos morais normalmente influem seja na própria positivação das

\footnotetext{
${ }^{9}$ Esta concepção distorcida sobre o positivismo jurídico já foi criticada por Bobbio sob a denominação de "positivismo ideológico", vede BOBBIO, Norberto. O positivismo jurídico: lições de Filosofia do Direito. São Paulo: Ed. Ícone, 2006, Capítulo VII. No mesmo sentido, NINO, Carlos Santiago. Introdução à análise do Direito. São Paulo: Ed. Martins Fontes, 2010, pp. 36-41.

${ }^{10}$ São as demonstrações de Hart, em HART, Herbert. O positivismo e a separação entre Direito e Moral. In HART, Herbert. Ensaios sobre Teoria e Filosofia do Direito. São Paulo: Ed. Elsevier, 2010, pp. 68-78.
} 
normas jurídicas seja nas suas aplicações, o que demandaria, portanto, uma ampliação da análise da Ciência do Direito de modo a abranger, a partir do Direito vigente, estas conexões. ${ }^{11}$

\section{Quinto minuto}

Assim como se mostram excêntricas e disparatadas as imagens de um cientista ou observador que se recusasse a reconhecer que a água evapora à temperatura de $100^{\circ} \mathrm{C}$ e 1 "atm.", que inadmitisse o fato do Sol erguer-se no céu todas as manhãs por ação dos movimentos de nosso planeta, ou, ainda, que se lamentasse pelas gotas de chuva caírem sob efeito da gravidade, revelase sem sentido que um teórico ou cientista do Direito pretenda afirmar a não juridicidade ou vigência de normas que, independentemente de sua manifestação, intervenção ou crítica, continuarão a ser aplicadas e impostas na realidade social que o circunda. O positivismo jurídico, como jusfilosofia sobre a metalinguagem que é a disciplina de estudo do Direito, não tem a faculdade, poder ou legitimidade para deliberar sobre o conteúdo ou justiça das normas jurídicas. As posições pessoais dos teóricos do Direito sobre o valor dos preceitos empiricamente atuantes não têm o privilégio de revogar ou alterar a facticidade da vigência das normas.

Em outra ótica, não é minimamente racional atribuir a uma determinada vertente de idéias teorias, filosofias ou abordagens científicas, quaisquer que sejam suas propostas - a responsabilidade pela ocorrência de qualquer acontecimento, bom ou ruim, no mundo dos fatos. A humanidade que provou do fruto da árvore do conhecimento e já reconheceu a morte de Deus deveria saber que a condição de liberdade imposta aos homens os condena ao eterno fardo da escolha e definição dos comportamentos a serem adotados por si e observados pelos demais. Às coletividades e indivíduos concretos - livres, perigosamente livres, virtuosamente livres - sempre cabem as responsabilidades por suas escolhas e as consequências daí geradas. Idéias não matam nem promovem o bem coletivo; culpar o positivismo jurídico é desconsiderar as responsabilidades humanas por seus atos. Fazer justiça e tornar o Direito justo é o que deveria mover todos os homens que, detendo o poder, positivam o Direito; e isto, aceite-se ou não, não passa pelo crivo das vontades dos estudiosos do fenômeno jurídico.

\section{Conclusão}

O estudo positivista do Direito pretende, simplesmente, analisar e produzir conhecimento sobre as normas que efetivamente regulam compulsivamente os comportamentos nos agrupamentos sociais. Não desconsidera, porém, a importância e necessidade de especulações filosóficas, axiológicas ou sociológicas sobre seu conteúdo e valor, mas as remete a outras e específicas disciplinas. O Direito, relacionando-se intimamente com o próprio poder imperante em uma certa sociedade, torna-se vinculante independentemente dos pareceres acadêmicos sobre sua

\footnotetext{
${ }^{11}$ Cf. WALUCHOW, Wilfrid. Legal positivism, inclusive versus exclusive. In E. Craig (Ed.), Routledge Encyclopedia of Philosophy. London. Disponível na Internet: http://pt.scribd.com/doc/56008841/Waluchow-Legal-PositivismInclusive-Versus-Exclusive, acesso em 03/10/2012. No Brasil, tratando sobre o ponto, DIMOULIS, Dimitri. Positivismo Jurídico: introdução a uma teoria do direito e defesa do pragmatismo jurídico-político. Op. cit., p. 134.
} 
justiça: o poder, de onde nasce o Direito, não pede licença a direitos naturais, normas da razão ou, muito menos, a opiniões de juristas. Assim como as górgonas ${ }^{12}$, que na mitologia grega transformavam em pedra os mais hábeis guerreiros que se atrevessem a fitar os seus olhos, o Direito, nas sombras do poder, sempre se impõe e realiza-se mesmo perante as mais justificadas e legítimas aspirações de justiça. Frente ao poder mesmo as mais iluminadas vontades se curvam, paralisando-se como pedras, incapacitadas de opor qualquer resistência às suas determinações. Fazer o Direito justo é uma possibilidade; a responsabilidade por sua realização depende dos homens, guiados por suas virtudes e pelos arranjos fáticos de poder.

\section{Referências}

ARENDT. Hannah. Origens do Totalitarismo: Anti-semitismo, imperialismo, totalitarismo. São Paulo: Ed. Companhia das Letras, 2009.

BOBBIO, Norberto. O positivismo jurídico: lições de Filosofia do Direito. São Paulo: Ed. Ícone, 2006.

DIMOULIS, Dimitri. Positivismo Jurídico: introdução a uma teoria do direito e defesa do pragmatismo jurídico-político. São Paulo: Ed. Método, 2006.

HART, Herbert. O conceito de Direito. $5^{\text {a }}$ ed. Lisboa, Portugal: Ed. Calouste Gulbenkian, 2007. O positivismo e a separação entre Direito e Moral. In HART, Herbert. Ensaios sobre Teoria e Filosofia do Direito. São Paulo: Ed. Elsevier, 2010.

LOSANO, Mario G. Sistema e estrutura no Direito. Volume II. São Paulo: Ed. Martins Fontes, 2010.

MÜLLER, Ingo. Los Juristas del Horror. Bogotá, Colombia: Ed. Alvaro Nora, 2009.

NINO, Carlos Santiago. Introdução à análise do Direito. São Paulo: Ed. Martins Fontes, 2010.

NOVAIS, Jorge Reis. Contributo para uma teoria do Estado de Direito. Lisboa, Portugal: Ed. Almedina, 2006.

RADBRUCH, Gustav. Cinco minutos de filosofia do Direito. In RADBRUCH, Gustav. Relativismo y Derecho. Bogotá, Colombia: Ed. Editorial Temis, 2009.

RAÓ, Vicente. O Direito e a Vida dos Direitos. 6a . São Paulo: Ed. Revista dos Tribunais, 2004. VAN CAENEGEM, R. C. Uma Introdução Histórica ao Direito Constitucional Ocidental. Lisboa, Portugal: Ed. Calouste Gulbenkian, 2009.

\footnotetext{
${ }^{12}$ Assim já se manifestava Hans Kelsen: "O problema do direito natural é o eterno problema do que está por trás do direito positivo. E quem procura uma resposta não encontra - temo - nem a verdade absoluta de uma metafísica, nem a justiça absoluta de um direito natural: quem levanta o véu e não fecha os olhos é ofuscado pela Górgona do poder.", Apud LOSANO, Mario G. Op. cit., p.121.
} 
WALUCHOW, Wilfrid. Legal positivism, inclusive versus exclusive. In E. Craig (Ed.), Routledge Encyclopedia of Philosophy. London. Disponível na Internet: http://pt.scribd.com/doc/56008841/Waluchow-Legal-Positivism-Inclusive-Versus-Exclusive, acesso em 03/10/2012. 